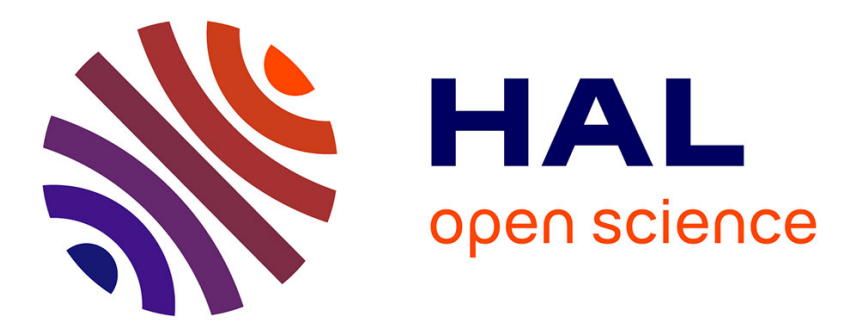

\title{
When Increasing the Strength of the Argument Becomes Counterproductive: The Role of Argumentative Markers in the Arousal of the Psychological Reactance
}

Vincent Coppola, Fabien Girandola

\section{- To cite this version:}

Vincent Coppola, Fabien Girandola. When Increasing the Strength of the Argument Becomes Counterproductive: The Role of Argumentative Markers in the Arousal of the Psychological Reactance. Journal of Language and Social Psychology, 2018, 37 (4), pp.475-496. 10.1177/0261927X17717038 . hal-03175645

\section{HAL Id: hal-03175645 \\ https://hal.science/hal-03175645}

Submitted on 11 Jan 2022

HAL is a multi-disciplinary open access archive for the deposit and dissemination of scientific research documents, whether they are published or not. The documents may come from teaching and research institutions in France or abroad, or from public or private research centers.
L'archive ouverte pluridisciplinaire HAL, est destinée au dépôt et à la diffusion de documents scientifiques de niveau recherche, publiés ou non, émanant des établissements d'enseignement et de recherche français ou étrangers, des laboratoires publics ou privés. 
When increasing the strength of the argument becomes counterproductive.

The role of some argumentative markers in the arousal of the psychological reactance

\section{Vincent Coppola $^{1}$ and Fabien Girandola ${ }^{2}$}

Abstract: the rationale of this study is that by stressing the argumentative force of the message, and thus orientating its processing, scalar adverbs are likely to be processed as an attempt to influence the decision making as regard the message advocacy and consequently trigger some aversive reactions in the recipients. To support this claim, an experiment is conducted in a context of a (campus) health promotion program dealing with HIV infection. It shows that the introduction of such adverbs in an epidemiological information report increases the cognitive and affective outcomes dealing with psychological reactance, and decreases the message acceptability and the behavioral intentions. It also shows that for the affective component of psychological reactance and message acceptability, these effects occur especially when the source of the message is perceived as authoritative. The persuasiveness of such linguistic items in the context of health communication is addressed in the conclusion of the study.

Keywords: persuasion, reactance, argumentative markers, pragmatics, health communication.

\footnotetext{
${ }^{1}$ University Paul Sabatier, LERASS, Toulouse, France

${ }^{2}$ University of Aix-Marseille, Aix-en-Provence, France

Corresponding Author:

Vincent Coppola, LERASS, University Paul Sabatier, 115 route de Narbonne, 310177 Toulouse, France.

Email: vincent.coppola@iut-tarbes.fr
} 
Public health campaigns sometimes fail to reach their objectives because they are subjected to a set of resistance strategies elicited by the individuals they try to influence (Crossley, 2002). Indeed, it has been largely showed that in some cases, people may respond defensively to personally relevant health message, and sometimes, are likely to adopt a contrary behavior than the one they are asked to espouse (Van't Riet \& Ruiter, 2013). Originally theorized in 1960s, Brehm's (1966) and Brehm and Brehm's (1981) psychological reactance process has been offered as an important cause for these unfortunate outcomes and remains a relevant theoretical framework for research on persuasive health communication (Dillard \& Shen, 2005; Erceg-Hurn \& Steed, 2011; Quick \& Bates, 2010; Wagner, Howland, \& Mann, 2015; Wong, Harrison, \& Harvell, 2015).

Broadly speaking, studies on reactance have shown that the way the promotional health message is linguistically featured is of a critical importance, so that some kinds of words and expressions should be avoided given their damaging and hazardous consequences (Burgoon, Alvaro, Grandpre, \& Voloudakis, 2002; Quick, Shen, \& Dillard, 2013). Built on this reactance inducing language area of research, the current study aims at investigating the reactance effects of some particular adverbs defined as "scalar adverbs" and it is designed as follows. First, a brief overview of the "Psychological Reactance Theory" is presented with a focus on some message features which served in the past research to define the construct of "controlling language". Second, built on some tenets of the theory of the "Argumentation within Language", the rationale of the study is presented which amounts to addressing the role of some scalar adverbs in the "reactance effect". Third, along with this first research question, a second one is presented and consists in asking whether these "reactance effects" could be moderated by some source features. Fourth, a study in 
the context of a (campus) health promotion program dealing with HIV infection is offered as the empirical core of this contribution in response to these research questions.

\section{Reactance Theory within health communication area: An overview}

Broadly speaking, reactance theory is concerned with individuals' responses to influence attempts and emanates from the major assumption that people strongly cherish their right to choose what to do and what to think without external influence and interference, and consequently are prone to aversive reactions in front of what they perceive as a threat on their freedom to decide autonomously (Brehm, 1966; Brehm \& Brehm, 1981; Wicklund, 1974). Specifically, whenever people feel that their decision-making freedom is encroached and their autonomy is constrained in any way, they experience reactance, a motivational state aimed at reaffirming and reestablishing this sense of self determination, by rejecting this attempt of influence and acting in the opposite way, even when it is against their best interest (Brehm \& Mann, 1975; Sensening \& Brehm, 1968).

Given what they are intended to do, it is not surprising that educative campaigns and health care interventions are plagued with psychological reactance (Rains \& Turner, 2007; Richards \& Banas, 2015). In a context of "health resistance" (Crossley, 2001), messages are highly likely to be seen as "trying too hard" to urge recipients to take the advocated position, and it is close for some message features to make the persuasive intent too obvious and further generate reactance, since it has largely been demonstrated that the perceived intent to persuade produces outcomes that are consistent with the theoretical predictions of reactance theory (Benoit, 1998; Heller, Pallack, \& Picek, 1973).

In this area of research, the most common way of increasing pressure in the persuasive message and enhancing its freedom-threatening character has consisted in 
manipulating the way it is worded and phrased (Miller, 2015). Scholars referred to this language feature with sometimes different labels, such as "controlling language" (Miller, Lane, Deatrick, Young, \& Potts, 2007), "forceful language" (Dillard \& Shen, 2005; Quick \& Considine, 2008), "dogmatic language" (Quick \& Stephenson, 2008; Shen, 2014), "explicit language" (Quick \& Stephenson, 2007a; Wagner, Howland, \& Mann, 2015), “domineering language" (Dillard, 2014; Quick, Shen, \& Dillard, 2013), and "assertive language" (Baek, Yoon, \& Kim, 2015; Kronrod, Grinstein, \& Wathieu, 2012).

As far as we know, this type of reactance-inducing message until now has been operationalized with a set of authoritative wordings pertaining to imperatives and absolute allegations such as "You simply have to do it [...] Do it because you have to [...] Stop the denial [...] Drink responsibly [...] There is really no choice [...] No other conclusion makes any sense [...] Any reasonable person has to agree that [...] You cannot deny that" (Dillard \& Shen 2005, pp. 152-153) or "It is impossible to deny [...] Any reasonable person absolutely has to agree that [...] You must start right now" (Quick \& Considine, 2008, p. 491). ${ }^{1}$ Furthermore, psychological reactance theory has been advanced to explain why language intensity sometimes could decrease persuasion (Buller, Borland, \& Burgoon, 1998; Burgoon \& King, 1974; Smith, 1977) and as Shen (2010) noted: "most communication scholars have mainly focused on linguistic and lexical features that tend to induce psychological reactance, such as language intensity" (p. 397). This Shen's (2010) assertion is particularly relevant in the context of the current study because it suggests that other linguistic features could be investigated in order to see whether they could work as "threat-to-choice language" and make the message processed as a "freedom-limiting message". The following section will address this question by focusing on a particular class of adverbs referred to as "scalar adverbs" in linguistics. 
Scalar adverbs as argumentative markers: A new insight into the reactance-inducing language

Scholars in linguistics interested in the persuasiveness of language investigated "scalar adverbs" such as "already" (Apotheloz \& Nowakowska, 2011; Michaelis, 1996), "almost" (Jarvella \& Lundquist, 1994; Van Gerrevink \& De Hoop, 2007; Winterstein \& Schaden, 2011), "even" (Kay, 1990; Snoeck-Henkemans, 2010), "only" and "more than"(Fahnestock, 1998; Jarvella \& Mathieu, 2000) and claimed that, given the rhetorical use which can be made of them, they make of the statements into which they are integrated, better candidates for the role of argument, increasing the persuasiveness of a piece of writing (Jayez \& Tovena, 2008). For instance, Van Gerrevink and De Hoop (2007) argued that: "given a situation where reality does not support a certain point he wants to make, the speaker can use a formulation with almost to make a statement that twists reality in such a way that it does support the conclusion" (p. 233).

However, in the area of pragmatics, and particularly in sight of Anscombre and Ducrot's $(1976,1983)$ "Argumentation Theory", it has been largely claimed that scalar adverbs such as almost, only, even, at least, already, also direct the interlocutor for the recovering of the argumentative orientation of the utterance in which they occur, and thus the underlying communicative intention reflected by that utterance (Champaud \& Bassano, 1987; Fraser, 1998; Holtgraves, 2008). Anscombre \& Ducrot (1983) argued that: "the presence of some morphemes (nearly for instance) in some sentences gives an intrinsic argumentative orientation to these sentences, predisposing them to be used in some types of conclusions rather than others (p. 149). Similarly, Defrise and Nirenburg (1990, p. 219) claimed that: "texts have a well-defined argumentative structure which reflects the 
producer's current goals [...] The argumentative structure of a text is realized (or, in text understanding, detected) through linguistic means such as the use of scalar adverbs ("only", "even", "almost", etc.)".

This "meaning is orienting" view of the language in the Anscombre and Ducrot's (1983) framework lies in its conceptualization of meaning as a set of instructions and directions linguistically embedded in the sentence, and as such reflecting its argumentative orientation. Ducrot (1988) claimed that: "The meaning of an utterance includes, as an integral, constitutive part of it, the form of influence called argumentative force. Meaning, for an utterance, is orienting" (p. 3). Within this instructional approach, scalar adverbs are defined as "argumentative operators" whose primary function is to constrain the recipient's processing of the utterance, which amounts to saying that for the speaker or message producer, to make use of them consists in directing the addressee toward a given conclusion (Foolen, 1996; Moeschler, 2015; Plantin, 2002; Verhagen, 2008).

Given these rationales, it was reasoned that, by stressing the argumentative orientation of the message, and thus constraining the reasoning, these linguistic items could be processed by the recipient as a clear attempt to influence his decision making as regard the message advocacy and consequently could trigger some cognitive and affective outcomes dealing with psychological reactance. It was thus hypothesized that:

Hypothesis 1: The presence of scalar adverbs within an epidemiological information message will have the effect of increasing the perceived threat to choice.

Hypothesis 2: The presence of scalar adverbs within an epidemiological information message will have the effect of increasing the psychological reactance. 
Hypothesis 3: The presence of scalar adverbs within an epidemiological information message will have the effect of decreasing the message acceptability.

Hypothesis 4: The presence of scalar adverbs within an epidemiological message will have the effect of decreasing the agreement with the message advocacy.

Hypothesis 5: The presence of scalar adverbs within an epidemiological message will have the effect of decreasing the intention to comply with the message advocacy.

\section{When the use of expertise backfires: The aversive effect of the authoritative figure}

In the area of persuasion, source's characteristics matter (Brinol \& Petty, 2009; Pornpitakpan, 2004). Although "perceived expertise" has been stated as an important factor for persuasion, a large amount of research on message source effects also focused on "perceived similarity" and demonstrated that in some circumstances a perceivably similar layperson peer source could have a relatively stronger impact than an expert one (Paek, Hove, Jeong, \& Kim, 2011). Researchers also demonstrated that these source's characteristics are not without consequences on the outcomes dealing with psychological reactance. For instance, it has been shown that expert and authoritative sources are likely to elicit more reactance than non-expert or non-authoritative sources (Bushman \& Stack, 1996; Pennebaker \& Sanders, 1976; Wicklund, 1974). In an early study by Brehm and Brehm (1981), participants were less likely to agree with a message strongly advocating teaching machines when it was attributed to a prominent professor than when it was attributed to a high school student. Silvia (2005) found that perceived interpersonal similarity with a communicator reduced reactance by reducing the level of perceived threat from a controlling message. 
Studying this particular topic in a health communication context, Pavey and Sparks (2009) found that a credible identified source, compared to an anonymous one, increased highly reactant individuals' perceptions of threat to decision-making freedom and therefore lead to less acceptance of the risk information message. Bushman (1998) found that warnings about fatty food from authoritative sources were more likely to draw consumers than to repel them and Snyder and Blood (1992) found similar results in their alcohol warning study with young adults. In the Gans's (2014) study about HPV vaccination, findings supported the choice of a non-expert young girl rather than a serious-looking authoritative expert as the spokesperson to deliver the message. Interested in the persuasive effects of entertainment-education messages, Moyer-Gusé (2008, p. 415) argued that "using peers to deliver persuasive risk messages can be an effective persuasive strategy because peers are seen as less authoritative and controlling [...] thus arousing less reactance" and a similar assumption originated the Crano, Siegel, Alvaro and Patel's (2007) study dealing with antiinhalant appeals. Similarly, Ahn, Paek, and Tinkham (2009) found that a controlling message with a peer source (i.e. similarity) versus doctor source (i.e. expertise) was more effective in terms of attitudes towards the PSA (more favorable), heavy drinking (less favorable) and intention not to drink heavily.

Consequently, based on this past research, along with the issue related to the role of scalar adverbs in the psychological reactance outcomes, it was also reasoned that the use of such an adverbial marking could be even more damaging if the message was delivered by an authoritative source. Thus it was predicted that the effects of scalar adverbs on the perceived threat to choice (see $\mathrm{H} 1$ ), psychological reactance (see $\mathrm{H} 2$ ), message acceptability (see H3), attitude toward the message advocacy (see $\mathrm{H} 4$ ), and behavioral intention (see $\mathrm{H} 5$ ) would occur, especially as the message would result from an authoritative source. Thus, 
whether this set of "reactance effects" related to the linguistic factor could be moderated by the source's factor was also a research question in the current study.

\section{Method}

\section{Independent variables}

In a text presented as an epidemiological report, adverbial marking (i.e. linguistic factor) was manipulated in order to create two versions as follow: a version that contained no scalar adverb ("low marking" condition) and a version whose some statements contained a scalar adverb ("high marking" condition). For instance, in the "low marking" version, it was stated that: "HIV contaminates 6000 new persons per year [...] 3500 HIV infections have been registered from January to June [...] 200 new cases occurred during the last six months for the 18 to 25 -year-old peoples. Including the number of peoples who still do not know that they are positive, this number is superior to 200", whereas in the "high marking" condition, the same information was stated as follow: "HIV contaminates up to 6000 new persons per year [...] Already 3500 HIV infections have been registered just for the period from January to June [...] Almost 200 new cases occurred during the last six months for the 18 to 25 -year-old peoples, and even more than 200 , by including the number of peoples who still do not know that they are positive".

As regards the communicator presented in this study as the author of the message (i.e. source factor), one was described as being "Professor Dr. Tom Markus", identified as a physician about whom it was stated that he was "the director of the Preventive Medicine and Health Promotion Department from the same university", responsible for providing services and information to students about their health ("high authoritative" source condition), whereas the other was presented as being "Tom Markus", identified as "a 
student" from the same age group about whom it was stated that he was "the coordinator of the Health and Wellness Club", namely a students' association from the same college, whose the purpose was described as in the high authoritative condition ("low authoritative" source condition).

\section{Dependent variables}

Perceived source authority. Participants were asked to indicate on a scale from 1 "no, not at all" to 7 "yes, absolutely" to what extent they considered the communicator as: "qualified to give his opinion on the message issue", "well trained to talk about the message issue" and "well informed on this topic". ${ }^{2}$ Participants' responses to these three Likert-type scale items were averaged to obtain a general index of the perceived source authority (Cronbach's $\alpha=$ $.93)$.

Perceived threat to freedom to choose. Participants were asked to indicate on a scale from 1 "no, not at all" to 7 "yes, absolutely" to what extent they were agree with the following statements: "The message threatened my freedom to choose", "The message tried to make a decision for me", "The message tried to manipulate me", and "The message tried to pressure $m e^{\prime \prime}$. Participants' responses to these four Likert-type scale items were averaged to obtain a general index of the perceived threat to freedom (Cronbach's $\alpha=.97)$.

Anger arousal. Participants indicated on a scale from 1 "no, not at all" to 7 "yes, absolutely" how "irritated", "angry" and "annoyed they felt while reading the message". These three items were combined into a single overall measure of anger arousal (Cronbach's $\alpha=.94)$.

Message acceptability. Participants indicated on a scale from 1 "no, not at all" to 7 "yes, absolutely" how "interesting", "helpful" and "relevant" was the message. Participants' 
responses to these three items were averaged to create a general index of the message acceptability (Cronbach's $\alpha=.96)$.

Attitude toward the message advocacy. Participants were asked to indicate on a scale from 1 "no, not at all" to 7 "yes, absolutely" to what extent they were agree with the following statements: "I agree with what the message recommends", "I endorse the claim made in the message", "Having safer sex is necessary", and "Having safer sex is wise". These four items were combined into a single overall measure of attitude toward the message advocacy (Cronbach's $\alpha=.98)$.

Behavioral intention. Participants indicated on a scale from 1 "no, not at all" to 7 "yes, absolutely" to what extent they agree with the following items: "Right now, I am determined to use a condom when having sexual intercourse with a casual partner", "Right now, I am motivated to use a condom when having sexual intercourse with a casual partner", and "Right now, I am inspired to use a condom when having sexual intercourse with a casual partner". For this measure, alpha reliability was .98

Cognitive response. Participants were provided with a paper sheet with 10 boxes and instructed as follows: "we are now interested in what you were thinking about as you were reading the message. Simply write down the first thought and idea that came to your mind in the first box, the second idea in the second box, etc. Please put only one idea or thought per box. You should try to record only those ideas that you were thinking while you were reading the message. You will have three minutes to list all of these thoughts and ideas. Please, be completely honest and list all of the thoughts you have had" (adapted from Petty and Cacioppo, 1977, p. 648). 
Two coders, blind to the experimental hypotheses, were instructed to evaluate whether these reported thoughts were relevant to the message issue ("HIV/AIDS is now controlled", "The disease is still dangerous", "To get informed about HIV/AIDS is important", "To be infected is not as serious as before", "I am not afraid about HIV/AIDS", "Condom sometimes is not necessary", "Even to my worst enemy, I would recommend to use condom", etc.) or not ("I feel very tired at the moment", "Maybe I will success the next exam", "I feel nervous and I have to control myself", etc.). Intercoder agreement for this first step was on $92 \%$ of the collected thoughts and discussions between coders and the experimenter served to resolve the disagreements.

The same coders were asked to consider the remaining data and judge whether, as regards the message argumentativeness, the message advocacy and the source of the message, they were supportive thoughts ("This message has to be considered", "This appeal is of a critical importance for young adults", "The condom remains the solution to promote among populations at risk", "Peoples less than 20 years have to be informed by such an appeal"), neutral thoughts ("HIV/AID is a sexual transmitted infection", "The last time I talked about HIV/AIDS, it was with a friend", "HIV/AIDS appears thirty years ago", etc.), or negative thoughts ("Condom use should remain a private and personal decision", "Money spent in these campaigns should be used to solve the unemployment problem", "The cancer disease is a far worse than AIDS", "This kind of appeal only serve to scare the naive peoples", etc.). Again, intercoder agreement was on $83 \%$ of the remaining thoughts with disagreements resolved by discussions between the experimenter and the coders. Finally, the total number of unfavorable thoughts was used in the subsequent data analyses as the cognitive component of state reactance. 


\section{Procedure}

All the participants $(\mathrm{N}=187$ ) were $18-21$ years old and recruited at the University Institute of Technology of Tarbes in the Department of Corporate and Administrative Management. The study was conducted during the courses where they were around 30 per class, so that for each session, it was possible to randomly assign the participants to one of the four conditions corresponding to the 2 (adverbial marking) $\times 2$ (source authority) betweensubjects design described before.

The experimental session began with an introductory speech of about 15 minutes during which participants were told that the academic staff of their university was initiating a "Student Health Program \& Plan" so that once a month, a session would be organized to inform them about certain risks to which the young adults aged $20-25$ years are frequently exposed. This was designed to justify the introduction of the first booklet containing the information message stimulus within which the experimental design was embedded. To justify the presentation of the dependent variables booklet for this "first" session, participants were also told that a group discussion would be organized at the end of this session, so that it was necessary to collect some of their opinion by means of an anonymous questionnaire.

On the first page of the message stimulus booklet, the source factor was manipulated as follows. In the "high authoritative source" condition, the "Preventive Medicine and Health Promotion Department" was presented by means of a letter drafted by its "director, Professor Dr. Tom Markus, whose researches on contagious diseases were world-famous"; whereas in the "low authoritative source" condition, the "Health and Wellness Club" was similarly described by its "coordinator, Tom Markus, a student" from the same college as the 
participants. Phone numbers, staff and hours of duty office were indicated so that the participants could take an appointment if they wished. On the second page of the same booklet was manipulated the message stimulus. At the top, the message topic appeared by means of the following phrasing:"HIV/AIDS: Let's take stock of the situation and then let's decide". Then the experimental message was delivered and it consisted of twelve statements describing the current epidemiological situation of HIV infection (i.e. prevalence and incidence of HIV). The linguistic manipulation was embedded in some statements, in such a manner that in the "adverbial high marking" condition, five statements contained scalar adverbs whereas in the "adverbial low marking", they did not. The final sentence of the message concluded as follow: "Now, you know. Please protect yourself" and was the same in each experimental condition.

Participants were instructed to read the first booklet and to fill the second one. No time constraint was imposed during the session but to make the participants engaged in an effortful processing of the information, we informed them that they needed to pay attention to the message content in order to participate to the latter group discussion. Once all the questionnaires were collected, subjects were invited to discuss about HIV transmission, and then they were thanked and dismissed. The debriefing took place during a class where all the students were gathered in a lecture theatre, after all the experimental sessions were performed.

\section{Results}

\section{Perceived source authority (manipulation check)}

The authoritativeness of the source was evaluated as higher when she was identified as an institutional authority figure than as a college student peer. An independent sample t-test 
revealed that subjects in the high authoritative source condition judged the source of the appeal as more authoritative than subjects in the low authoritative source condition $\left(\mathrm{M}_{\mathrm{high}}=\right.$ 4.59 vs. $\left.M_{\text {low }}=3.20, t=13.02, \mathrm{df}=185, \mathrm{p}<.0001\right)$. This result indicates that participants perceived source authoritativeness as intended in the study design and suggests that the operationalization of the source authority factor was relevant.

\section{Perceived threat to attitudinal freedom (see Table 1)}

A $2 \times 2$ factorial ANOVA revealed that the participants who were exposed to the adverbial high marking version found the message to be more threatening as regards their freedom to choose than participants who received the adverbial low marking version $[M=3.82$ vs. 2.84 , $\left.F(1,185)=26.10, p<.0001, \eta^{2}=0.123\right]$. The same ANOVA also showed that participants who received the message from the high authoritative source judged the message to be more controlling than participants who were exposed to the low authoritative source $[M=3.52$ vs. 3.10, $\left.F(1,185)=4.26, p=.04, \eta^{2}=0.02\right]$. Although the interaction between the two factors did not reach statistical significance $[F(1,183)=2.66, p=.104]$, further analyses revealed that the adverbial high marking (vs. low marking) enhanced the perceived threat to attitudinal freedom in a greater extent when the communicator was a high authoritative source $\left[M_{\text {high marking }}=4.19\right.$ vs. $\left.M_{\text {low marking }}=2.90, F(1,183)=23.81, p<.0001, \eta^{2}=0.115\right]$ than a low authoritative source $\left[\mathrm{M}_{\text {high marking }}=3.44\right.$ vs. $\mathrm{M}_{\text {low marking }}=2.77, \mathrm{~F}(1,183)=6.14, \mathrm{p}<.02$, $\left.\eta^{2}=0.032\right]$,

Table 1 near here 


\section{Anger arousal (see Table 1)}

Similar statistical analyses showed that participants dealing with adverbial high marking version reported having experienced more negative feeling while they were processing the message than did their counterparts in the adverbial low marking condition $[M=2.89$ vs. 1.98, $\left.F(1,185)=33.37, p<.0001, \eta^{2}=0.153\right]$. This was also the case with a reliable trend toward significance for the participants exposed to the high authoritative source compared with those who were leading to identify the communicator as a low authoritative source [M $=2.58$ vs. $\left.2.26, F(1,185)=3.68, p=.056, \eta^{2}=0.019\right]$. A significant interaction effect was also observed between the two factors $\left[F(1,183)=5.25, p=.023, \eta^{2}=0.028\right]$.

Again planned contrasts were performed to further explore the hypothesized moderating role of source authority factor. As for the perceived threat to attitudinal freedom, the stronger anger experienced by the participants in reaction to the adverbial high marking version (vs. low adverbial marking) was mitigated in the low authoritative source condition $\left[M_{\text {high marking }}=2.54\right.$ vs. $M_{\text {low marking }}=1.98, F(1,183)=6.25, p<.02, \eta^{2}=$ $0.033]$, compared to the high authoritative source condition $\left[M_{\text {high marking }}=3.24\right.$ vs. Mlow marking $\left.=1.96, \mathrm{~F}(1,183)=34.23, \mathrm{p}<.0001, \eta^{2}=0.157\right]$

\section{Message acceptability (see Table 2)}

The statistical analyses indicated that the message in the adverbial high marking condition was subject to a significantly lesser acceptance than the one in the adverbial low marking condition $\left[M=3.15\right.$ vs. $\left.3.96, F(1,185)=20.33, p<.0001, \eta^{2}=0.099\right]$. When the author of the message was identified as a high authoritative source, the message was also lower valued as regards its relevance than when he was perceived as a low authoritative source, but the statistical analysis failed to reach conventional significance $[M=3.42$ vs. $3.72, F(1,185)=$ 
2.53, $\left.p=.113, \eta^{2}=0.013\right]$. Again a significant interaction effect was observed between the two factors $\left[F(1,183)=4.27, p=.04, \eta^{2}=0.023\right]$. As regards the moderating role of source factor on adverbial marking effects, similar patterns of results emerged. Planned comparisons showed that the adverbial high marking (vs. low marking) lowered the message acceptability in a greater extent when the source of the message was a high authoritative source $\left[M_{\text {high marking }}=2.82\right.$ vs. $\left.M_{\text {low marking }}=3.98, F(1,183)=22.43, p<.0001, \eta^{2}=0.109\right]$ than a low authoritative source $\left[\mathrm{M}_{\text {high marking }}=3.50\right.$ vs. $\mathrm{M}_{\text {low marking }}=3.94, \mathrm{~F}(1,183)=2.99, \mathrm{p}=.085$, $\left.\eta^{2}=0.016\right]$

\section{Attitude toward the message advocacy (see Table 2)}

Participants who processed the message featured with an adverbial high marking were significantly less in agree with the message advocacy than participants who processed the message without such a marking $\left[M=3.44\right.$ vs. $\left.4.56, F(1,185)=24.68, p<.0001, \eta^{2}=0.117\right]$. This agreement was also lower in the high authoritative source condition than in the low authoritative source condition $\left[M=3.76\right.$ vs. $\left.4.28, F(1,185)=4.91, p=.028, \eta^{2}=0.026\right]$. A discrete interaction effect was also revealed by the statistical analysis $[F(1,183)=3.11, p=$ $\left..079, \eta^{2}=0.017\right]$ and the planned contrasts indicated that the detrimental effect of the adverbial high marking (vs. low marking) on attitude toward the message advocacy was more important when the communicator was a high authoritative source $\left[\mathrm{M}_{\text {high marking }}=2.98\right.$ vs. $\left.M_{\text {low marking }}=4.48, F(1,183)=23.84, p<.0001, \eta^{2}=0.115\right]$ than a low authoritative source $\left[M_{\text {high marking }}=3.92\right.$ vs. $\left.M_{\text {low marking }}=4.64, F(1,183)=5.27, p<.03, \eta^{2}=0.028\right]$. 


\section{Behavioral intention (see Table 2)}

The willingness to comply with the message advocacy, namely to use a condom when having sexual intercourse with a new or casual partner, was lower in the adverbial high marking condition than in the adverbial low marking one $[M=3.25$ vs. $4.43, F(1,185)=31.50, p<$ $\left..0001, \eta^{2}=0.145\right]$. This behavioral intention was also expressed with a lesser extent by the participants in the high authoritative source condition compared with the participants in the low authoritative source condition $\left[M=3.62\right.$ vs. $\left.4.10, F(1,185)=4.57, p=.034, \eta^{2}=0.024\right]$. Again, a near-significant interaction effect was indicated by statistical analyses $[F(1,183)=$ 3.07, $\left.p=.082, \eta^{2}=0.016\right]$ and the same pattern of results emerged from the planned contrasts, the damaging effect of the adverbial high marking (vs. low marking) being more important in the high authoritative source condition $\left[\mathrm{M}_{\text {high marking }}=2.82 \mathrm{vs.}\right.$ M low marking $=4.36$, $\left.\mathrm{F}(1,183)=28.54, \mathrm{p}<.0001, \mathrm{\eta}^{2}=0.135\right]$ than in the low authoritative condition $\left[\mathrm{M}_{\text {high marking }}=\right.$ 3.69 vs. $\left.M_{\text {low marking }}=4.50, \mathrm{~F}(1,183)=7.62, \mathrm{p}<.01, \eta^{2}=0.040\right]$.

\section{Cognitive responses (see Table 3)}

\section{Table 3 near here}

The number of negative thoughts listed by the participants (i.e. thought-listing task) was higher in the adverbial high marking condition than in the adverbial low marking one $[M=$ 1.58 vs. $\left.1.07, F(1,185)=9.02, p<.01, \eta^{2}=0.046\right]$, but did not differ significantly between the source conditions $[M=1.39$ vs. $1.24, F<1]$. No significant interaction appeared $(F=1.31$, $p=.25)$.

\section{Discussion}


The rationale for this study was to investigate the effects of some particular linguistic and lexical features referred to as "scalar adverbs" on a set of (persuasive) outcomes dealing with psychological reactance theory. ${ }^{3}$ It was assumed that, disseminated within a persuasive message (in the context of a health promotion program dealing with HIV infection and condom use), these adverbs would increase the argumentative orientation of the message so that they would reinforce in the recipient the feeling that he has been pressured to accept the advocated conclusion (i.e. the health recommendation). Said differently, it was reasoned that by enhancing the message argumentative force by means of these particular adverbs, the recipient would perceive that his autonomy to decide has been curtailed and thus, would react in an aversive manner with a blend of emotional and cognitive processes dealing with psychological reactance (i.e. the first set of hypotheses $H 1, H 2, H 3, H 4, H 5$ ). Given the empirical data of the study, one can consider that these hypotheses are supported. It was also predicted that these aversive outcomes associated with an adverbial high marking would be more pronounced when the author of the message would be identified as an authoritative source. This interaction hypothesis was clearly supported by the statistical analyses, except for the perceived threat to attitudinal freedom and the cognitive component of the psychological reactance (i.e. number of negative thoughts).

However, one limitation of this study is the possible confusion between "authoritativeness" and "perceived similarity", given the way the source considered as "low authoritative" was portrayed. A lot of scholars have shown that source-receiver similarity facilitates persuasion and intentions to adopt a specific health behavior (Phua, 2016; Salmon \& Atkin, 2003; Shiron Lu, 2013), and in the particular context of HIV interventions, a metaanalysis found that demographic and behavioral similarity between the source and recipients resulted in more positive behavior change (Durantini, Albarracin, Mitchell, Earl, \& 
Gillette, 2006). Other studies have demonstrated that the perceived interpersonal similarity was also a decisive moderator of reactance (Silvia, 2005). Consequently, it cannot be excluded that it is the perceived similarity that underlies the manipulation of the source factor in this study and is responsible for the observed patterns of results.

As far as we know, no study until now has addressed whether scalar adverbs could elicit psychological reactance so that the current study can be seen as a contribution to the reactance-inducing messages-related issue in the persuasive health communication area. However, in most of the previous studies on reactance, the construct of "controlling" or "forceful language" was operationalized by means of an increased use of imperative forms and absolute allegations such as "ought", "must" and "should", "have to", "do not", which explicitly and clearly stated how to think and what to do and leaved little doubt as to the source's intentions (for a review, see Miller, 2015; Rains, 2013). Yet, it should be noted that in the current study, such an authoritative wording style was not used in the appeal and the health recommendation was not stated by means of a peremptory formulation. ${ }^{4}$ So, even if scalar adverbs seem to make the message linguistically less explicit as regards its persuasive aim and maybe reflect a more disguised persuasive attempt, the fact remains that they entailed reactance processes in the context of the current study.

Whether scalar adverbs pertain to "controlling" and "forceful language" obviously remains a question to investigate in the future research on language and persuasion. And this is all the more necessary as these particular adverbs have been also considered as useful devices likely to increase the persuasiveness of their hosts (Jayez \& Tovena, 2008). Whether the effects reported in this study are contingent upon a sufficient number of reactanceinducing adverbs being presented is an important issue which could help to understand why sometimes scalar adverbs are effective, as asserted in the rhetorician's perspective 
(Fahnestock, 1998), and why sometimes they are not, as reported in this study. It could be hypothesized that they are effective provided that they are used with parsimony, but overused within the message, they could trigger reactance responses. So whether the quantity of scalar adverbs is of a critical importance could stimulate a future research and a curvilinear relationship between the number of adverbs and the attitude change could be anticipated.

How much any particular adverb considered in this study contributed to the reactance effects reported here is also an important issue. It cannot be ruled out that some scalar adverbs are more likely to strengthen the argumentative force of the message and consequently to trigger some reactance responses than others. For instance, Bassano (1991) characterized "almost" as a "privileged and basic argumentative marker" (p. 152), and similarly, Michaelis (1992) stated that "a given variety of already-style temporal precedence has an argumentative force insofar as assertions invoking it exploit the capacity of the addressee to derive from the already-bearing proposition a certain type of conclusion ( $p$. 337). In sum, future studies should examine the effects, both individually and in combination, of these scalar adverbs, as it has been suggested by some scholars interested in the powerful vs. powerless speech styles area of research (Hosman, 1989). ${ }^{5}$

Given that the study was realized in the context of a (campus) Hiv/Aids prevention intervention and safer sex promotion, it raises the question of whether the pattern of results reported here may owe something to the particular choice of topic. ${ }^{6}$ Indeed, one tenet of the Brehm's (1966) theory of psychological reactance is that the magnitude of the reactance experienced by the individual is directly related to the perceived importance of the behavior for which the freedom to choose is threatened. Studies have shown that for adolescents and 
young adults, sexual activity is considered as a private matter and refers to a behavioral dimension for which the freedom to choose is essential, so that some scholars recommended a choice and autonomy based education policy (Allen, 2011; Goldfarb \& Constantine 2011; McKenzie, Hedge, \& Enslin, 2016). So it is reasonable to assume that the experimental message under study was particularly perceived as intrusive. In a future study, this dimension could be measured by asking to the participants to what extent they expect to have the freedom to decide when, where, how, and with whom to have sexual intercourses, and could be treated as a moderating variable. In relation to the issue raised above, it could be also examined whether a similar pattern of results would appear if the health message referred to a behavior or a practice for which the freedom to choose is less prominent.

Would these linguistic items make the threat to freedom salient and thus induce reactance if the health topic was a new one, in respect of which the individuals have no knowledge and receive information for the first time. Maybe the perception of intrusiveness in reaction to this adverbial marking could be softened insofar as the subjects could perceive that in such a case, the message is legitimated and is in their best interest. Again it has been contended that if a justification or an explanation for the threatened or lost freedom was perceived by the individual, psychological reactance was tempered (Brehm, 1966).

Another study could examine whether the effects of this adverbial (high) marking could be moderated by the recipient's health orientation, defined as an intrinsic motivation to engage in healthy attitudes and behavior (Dutta-Bergman, 2005). It could be hypothesized that these effects would occur to a lesser extent, or even be completely reversed, in peoples who are highly oriented toward their health. In a similar way, another study could cross this 
linguistic factor with trait reactance proneness (Hong, 1992) and hypothesizes that peoples high in trait reactance would react aversively in response to this adverbial marking, considering that their autonomy to decide is clearly threatened, whereas peoples low in trait reactance would accept the message and comply with its advocacy, considering that the message is made of strong arguments. ${ }^{7}$

It could also be interesting to examine how this adverbial marking factor could interact with the need for cognitive closure, defined as a personality-based tendency to prefer "an answer on a given topic, any answer, as compared to confusion and ambiguity “(Kruglanski, 1990, p.337, italics in original). Since these linguistic cues are used in a given sentence with the primary function of bringing to the recipient's attention (and directing him toward) a particular kind of conclusion (Verhagen, 2008), they could be of a high relevance for people high in need for cognitive closure, hypothesized to prefer order and predictability, to "seize" upon early information and quickly "freeze" on judgements it implies, and to be hastened to arrive at a clear-cut conclusion (Webster \& Kruglanski, 1997), but not for people low in need for cognitive closure, who could process them as threat-to-choice language components. As a result, the former could react positively to the message (i.e. acceptance and compliance), while the latter could be reactant (i.e. boomerang effect). ${ }^{8}$ The future studies suggested here are aimed at examining some factors that might exacerbate or dissipate reactance and as such are related to a current call for more research on potential moderators of psychological reactance (Rains, 2013; Shen, 2014).

\section{Conclusion}

Undoubtedly, the theory of psychological reactance has been a useful framework to explain why prevention efforts sometimes fail to produce the desired effects (Burgoon, Alvaro, 
Grandpre, \& Voloudakis, 2002; Dillard \& Shen, 2005), and it is expected to be advanced in the near future since several scholars recently called for further researches on message features that would arouse as well as mitigate psychological reactance (Quick, Shen, \& Dillard, 2013; Steindl, Jonas, Sittenthaler, Traut-Mattaush, \& Greenberg, 2015). By investigating the aversive effects of some linguistic cues referred to as "scalar adverbs", the current study echoes this claim and thus could provide prevention planners with some guidelines regarding how to design persuasive health messages without arousing reactance processes.

As noted in the theoretical backgrounds of this study, scalar adverbs have been viewed as powerful devices from a rhetorician's standpoint (Fahnestock, 1998), but the rationale of this contribution was that they also could work as controlling language and make the message a freedom-limiting message, given their argumentative orientation marking function (Anscombre \& Ducrot, 1983). Thus, this research could inspire the health message designers who could resort to these scalar adverbs as a powerful message feature, providing that a strategy likely to soften the perception of intrusiveness they conveyed is also planned. In a worldwide context of "HIV prevention fatigue" ${ }^{9}$ associated with risky sexual behavior (Fruchter, 2002; Godinho \& Veen, 2006; Plattner, 2015; Ritter, 2000; Stockman, Schwarcz, Butler, de Jong, Chen, Delgado, \& McFarland, 2004), maybe the current study will be of some interest as regard its practical implications in the broader context of public health campaigns.

\section{Acknowledgments}


The authors are very grateful for the constructive criticism provided by the anonymous reviewers and the editor Howie Giles, their insights were valuable in the revision of this article.

\section{Declaration of Conflicting Interests}

The author(s) declared no potential conflicts of interest with respect to the research, authorship, and/or publication of this article.

\section{Funding}

The author(s) received no financial support for the research, authorship, and/or publication of this article.

\section{$\underline{\text { Notes }}$}

1. Sample quotes illustrating the way of phrasing the threat to freedom as part of a broader persuasive appeal are reported in Rains's (2013, p. 54-57) meta-analytic review.

2. These items were adapted from McCroskey's (1966) measurement of source authoritativeness

3. It needs to be clarified that these adverbs have been characterized as "argumentative markers" by psycholinguists interested in the Anscombre and Ducrot's (1983) theory of argumentation (Bassano, 1991; Bassano \& Champaud, 1987).

4. Let's remind that the health recommendation was stated as follow "Now, you know. Please protect yourself" and was rigorously the same for all conditions. 
5. The fact that the study employed "generic" high-and low- adverbial marking could be considered as a methodological flaw insofar as it leaves unclear how much each of the adverbs under study contributed to the reactance effects. It must be clarified that the study did not aim at determining whether the linguistic items constituting the "adverbial marking" equally induce reactance but aimed at showing that when the "argumentative force" is increased, it may result in reactance effects. At the conceptual level, the message feature under consideration was the "argumentative force" or "argumentative orientation" (Anscombre \& Ducrot, 1976, 1983), and the use of the scalar adverbs was intended to increase this "force". Maybe the characterization of the message factor in terms of "argumentative force" instead of "adverbial marking" would have better reflected the rationale of this study.

6. The choice of a campus Hiv/Aids-prevention intervention and safer sex promotion as context for this study was motivated by the fact that a relaxation of preventive behaviors has been observed during the last years in peoples under 25 years old. Between 2007 and 2013 , the proportion of these peoples in the number of new infections increased by $24 \%$ (Lot, Smati, Montlahuc, Cazein, Barin, et al., 2015). Of course, this decision limits the generalization of the findings reported here, since it has been shown that reactant levels may vary based on age (Hong, Giannakopoulos, Laing, \& Williams, 1993; Woller, Buboltz, \& Loveland, 2007). Nevertheless, an importance was attached to the potential practical implications of this research given the epidemiological context at the time it was carried out. In some studies, HIV/AIDS prevention and condom promotion served as context for an application of Psychological Reactance Theory (Haynes, 2015; Quick \& Stephenson, 2007b). 
7. Although reactance was initially conceived as situation specific (Brehm, 1966), several scholars stated that it could be also considered as an individual difference variable and developed scales to measure person's transituational propensity to experience reactance (for a measure of trait reactance, see Hong, 1992; Hong \& Faedda, 1996). In the current study, participants' trait reactance proneness was not measured and it could be one limitation of this study.

8. This interaction hypothesis is suggested in light of the extensive research on persuasion that examined the matching between messages features and individual differences (for a review, see Brinõl \& Petty, 2005).

9. Maybe it would have been cautious to control for this "HIV prevention fatigue". One cannot rule out the possibility that some participants experienced a sense of weariness in reaction to the HIV prevention message and that such a feeling exacerbated psychological reactance process, in addition to a perception of intrusiveness given the adverbial marking.

\section{References}

Ahn, H., Paek, H. J., \& Tinkham, S. (2009). The persuasive effects of anti-binge drinking public service advertising on college students' binge drinking: The effectiveness of message sources, message appeals and their interactions. Paper presented at the 2009 annual convention of American Academy of Advertising, Cincinnati, $\mathrm{OH}$.

Allen, L. (2011). Young people and sexuality education. Rethinking key debates. New York, NY: Palgrave-McMillan. 
Apotheloz, D., \& Nowakowska, M. (2011). Déjà en emploi justificatif. In G. Corminboeuf, \& M. J. Béguelin (Eds.), Du système linguistique aux actions langagières (pp. 249-261). Brussells, Belgium: De Boeck-Duculot.

Anscombre, J. C., \& Ducrot, O. (1976). L'argumentation dans la langue. Langages, 42, 5-27. Anscombre, J. C., \& Ducrot, O. (1983). L'argumentation dans la langue. Brussells, Belgium: Mardaga.

Baek, T. H., Yoon, S., \& Kim, S. (2015). When environmental messages should be assertive: Examining the moderating role of effort investment. International Journal of Advertising, 34, 135-157.

Bassano, D. (1991). Opérateurs et connecteurs argumentatifs: Une approche psycholinguistique. Intellectica, 11, 149-191.

Bassano, D., \& Champaud, C. (1987). La fonction argumentative des marques de la langue. Argumentation, 1, 175-199.

Benoit, W. L. (1998). Forewarning and persuasion. In M. Miller, \& R. W. Preiss (Eds.), Persuasion: Advances through meta-analysis (pp. 139-154). Cresskill, NJ: Hampton Press Inc.

Brehm, J. W. (1966). A theory of psychological reactance. New York, NY: Academic Press.

Brehm, S. S., \& Brehm, J. W. (1981). Psychological reactance: A theory of freedom and control. New York, NY: Academic Press.

Brehm, J. W., \& Mann, M. F. (1975). Effect of importance of freedom and attraction to group members on influence produced by group pressure. Journal of Personality and Social Psychology, 31, 816-824. 
Brinõl, P., \& Petty, R. E. (2005). Individual differences in attitude change. In D. Albarracín, B. T. Johnson, \& M. P. Zanna (Eds.), The handbook of attitudes and attitude change (pp. 575-615). Mahwah, NJ: Lawrence Erlbaum.

Brinõl, P., \& Petty, R. E. (2009). Source factors in persuasion: A self-validation approach. European Review of Social Psychology, 20, 49-96.

Buller, D. B., Borland, R., \& Burgoon, M. (1998). Impact of behavioral intention on effectiveness of message features. Evidence from the family sun safety project. Human Communication Research, 24, 433-453.

Burgoon, M., Alvaro, E. M., Grandpre, J. R., \& Voloudakis, M. (2002). Revisiting the theory of psychological reactance: Communicating threats to attitudinal freedom. In J. P. Dillard \& M. Pfau (Eds.), The persuasion handbook: Developments in theory and practice (pp. 213-232). Thousand Oaks, CA: Sage.

Burgoon, M., \& King, L. B. (1974). The mediation of resistance to persuasion strategies by language variables. Human Communication Research, 1, 30-41.

Bushman, B. J. (1998). Effects of warning and information labels on consumption of full-fat, reduced-fat, and no-fat products. Journal of Applied Psychology, 83, 97-101.

Bushman, B. J., \& Stack, A. D. (1996). Forbidden fruit versus tainted fruit: Effects of warning labels on attraction to television violence. Journal of Experimental Psychology: Applied, 2, 207-226.

Champaud, C., \& Bassano, D. (1987). Argumentative and informative functions of French intensity modifiers 'presque', 'à peine' and 'à peu près': an experimental study on children and adults. Cahiers de Psychologie Cognitive, 7, 605-631. 
Crano, W. D., Siegel, J. T., Alvaro, E. M., \& Patel, N. M. (2007). Overcoming adolescents' resistance to anti-inhalant appeals. Psychology of Addictive Behaviors, 21, 516-524.

Crossley, M. L. (2001). 'Resistance' and health promotion. Health Education Journal, 60, 197204.

Crossley, M. L. (2002). Resistance to health promotion: A preliminary comparative investigation of British and Australian students. Health Education, 102, 289-299.

Defrise, C., \& Nirenburg, S. (1990). Meaning representation and text planning. In COLING-90: Proceedings of the $13^{\text {th }}$ conference on computational linguistics (Vol.3, pp. 219-224). Helsinki, Finland: Association for Computational Linguistics.

Dillard, J. P. (2014). Language, style, and persuasion. In T. M. Holtgraves (Ed.), The Oxford handbook of language and social psychology (pp. 177-187). Oxford, UK: Oxford University Press.

Dillard, J. P., \& Shen, L. (2005). On the nature of reactance and its role in persuasive health communication. Communication Monographs, 72, 144-168.

Ducrot, O. (1988). Topoi et formes topiques. Bulletin d'Etudes de Linguistique Française, 22, 1-14.

Durantini, M. R., Albarracín, D., Mitchell, A. L., Earl, A., \& Gillette, J. C. (2006). Influencial agents of behavior change for different genders, ethnicities, ages, and behaviorallydefined groups: A meta-analysis of HIV-prevention interventions. Psychological Bulletin, 132, 212-248.

Dutta-Bergman, M. J. (2005). Psychographic profiling of fruit and vegetable consumption: the role of health orientation. Social Marketing Quarterly, 11, 19-35. 
Erceg-Hurn, D. M., \& Steed, L. G. (2011). Does exposure to cigarette health warnings elicit psychological reactance in smokers? Journal of Applied Social Psychology, 41, 219237.

Fahnestock, J. (1998). Accommodating science: The rhetorical life of scientific facts. Written Communication, 15, 330-350.

Foolen, A. (1996). Pragmatic particles. In J. Verschueren, J. O. Ostman, J. Blommaert, \& C. Ulcaen (Eds.), Handbook of Pragmatics (pp. 1-24). Philadelphia, PA: John Benjamins.

Fraser, B. (1998). What are discourse markers? Journal of Pragmatics, 31, 931-952.

Fruchter, J. (2002). Colorado looks for new way to educate, avoid "Safer sex burnout". Colorado Daily: June 4, 2002. Available from: CDC National Prevention Information Network: News Record \# 35254.

Gans R. (2014). The politics of HPV vaccination advocacy: Effects of source expertise on effectiveness of a pro-vaccine message. Proceedings of the New York State Communication Association: Vol. 2013, Article 3. Available at: http://docs.rwu.edu/nyscaproceedings/vol2013/iss2013/3

Godinho, J., \& Veen, J. (2006). Illicit drug policies and their impact on the HIV epidemic in Europe. In S. Matic, J. V. Lazarus, \& M. C. Donoghoe (Eds.), HIV/AIDS in Europe. Moving from death sentence to chronic disease management (pp. 27-42). Copenhagen, Denmark: WHO Regional Office for Europe.

Haynes, M. D. (2015). Reversing the boomerang effect in persuasive health communication: Reducing psychological reactance to self-persuasion using inoculation and restoration 
treatments. (Unpublished Master's Thesis, Texas Christian University). Retrieved from https://repository.tcu.edu/handle/116099117/8324

Heller, J., Pallack, M., \& Picek, J. (1973). The interactive effects of intent and threat on boomerang attitude change. Journal of Personality and Social Psychology, 26, 273279.

Holtgraves, T. (2008). Automatic intention recognition in conversation processing. Journal of Memory and Language, 58, 627-645.

Hong, S. M. (1992). Hong's psychological reactance scale: A further factor analytic validation. Psychological Reports, 70, 512-514.

Hong, S. M., \& Faedda, S. (1996). Refinement of the Hong psychological reactance scale. Educational and Psychological Measurement, 56, 173-182.

Hong, S. M., Giannakopoulos, E., Laing, D., \& Williams, N. A. (1993). Psychological reactance: Effects of age and gender. Journal of Social Psychology, 134, 223-228.

Hosman, L. (1989). The evaluative consequences of hedges, hesitations, and intensifiers. Powerful and powerless speech styles. Human Communication Research, 15, 383406.

Jarvella, R. J., \& Lundquist, R. (1994). Scales in the interpretation of words, sentences, and texts. Journal of Semantics, 11, 171-198.

Jarvella, R. J., \& Mathieu, S. (2000). On judging quantities in text without expert knowledge. In R. Lundquist, \& R. J. Jarvella (Eds.), Language, text and knowledge (pp. 261-284). New York, NY: Mouton De Gruyter. 
Jayez, J., \& Tovena, L. M. (2008). Presque and almost: How argumentation derives from comparative meanings. In O. Bonami, \& P. Cabredo Hofherr (Eds.), Empirical issues in syntax and semantics, (Vol. 7, pp. 217-239). Paris, France: CNRS.

Kay, J. (1990). Even. Linguistics and Philosophy, 13, 59-111.

Kronrod, A., Grinstein, A, \& Wathieu, L. (2012). Go green! Should environmental messages be so assertive? Journal of Marketing, 76, 95-102.

Kruglanski, A. W. (1990). Motivations for judging and knowing: Implication for causal attribution. In E. T. Higgins \& R. M. Sorrentino (Eds.), Handbook of motivation and cognition (Vol. 2, pp. 333-368). New York, NY: Guilford Press.

Lot, F., Smati, J., Montlahuc, C., Cazein, F., Barin, F., et al. (2015). Découvertes de séropositivité VIH chez les jeunes en France, 2003-2013. BEH, 40-41, 744-751.

McCroskey, J. C. (1966). Scales for the measurement of ethos. Speech Monographs, 31, 6572.

McKenzie, A., Hedge, N., \& Enslin, P. (2016). Sex education: Challenges and choices. British Journal of Educational Studies, doi: 10.1080/00071005.2016.1232363

Michaelis, L. A. (1992). Aspect and the semantics-pragmatics interface: The case of already. Lingua, 87, 321-339.

Michaelis, L. A. (1996). On the use and meaning of already. Linguistics and Philosophy, 19, 477-502.

Miller, C. H. (2015). Persuasion and psychological reactance: The effects of explicit, highcontrolling language. In R. Shulze, \& H. Pishwa (Eds.), The exercise of power in 
communication: Devices, reception and reaction (pp. 269-286). London, UK: Palgrave McMillan.

Miller, C. H., Lane, L. T., Deatrick, L. M., Young, A. M., \& Potts, K. A. (2007). Psychological reactance and promotional health messages: The effects of controlling language, lexical concreteness, and the restoration of freedom. Human Communication Research, 33, 219-240.

Moeschler, J. (2015). Argumentation and connectives. How do discourse connectives constrain argumentation and utterance interpretations? In A. Capone, \& J. Mey (Eds.), Interdisciplinary studies in pragmatics, culture and society (pp. 653-676). New York, NY: Springer.

Moyer-Gusé, E. (2008). Toward a theory of entertainment persuasion: Explaining the persuasive effects of entertainment-education messages. Communication Theory, 18, 407-425.

Paek, H. J., Hove, T., Jeong, H. J., \& Kim, M. (2011). Peer or expert? The persuasive impact of You Tube public service announcement producers. International Journal of Advertising, 30, 161-188.

Pavey, L., \& Sparks, P. (2009). Reactance, autonomy and paths to persuasion: Examining perceptions of threats to freedom and informational value. Motivation and Emotion, 33, 277-290.

Pennebaker, J. W., \& Sanders, D. Y. (1976). American graffiti: Effects of authority and reactance arousal. Personality and Social Psychology Bulletin, 2, 264-267. 
Petty, R. E., \& Cacioppo, J. T. (1977). Forewarning, cognitive responding, and resistance to persuasion. Journal of Personality and Social Psychology, 35, 645-655.

Plantin, C. (2002). Argumentation studies and discourse analysis: The French situation and global perspectives. Discourse Studies, 4, 343-368.

Plattner, E. (2015). HIV and AIDS "fatigue" and sexual risk behavior among university students in Bostwana. Paper presented at the $12^{\text {th }}$ International AIDS Impact Conference. Amsterdam, Netherlands. Abstract retrieved from http://www.aidsimpact.com/2015/Academics/Programme/abstract/?id=2272

Pornpitakpan, C. (2004). The persuasiveness of source credibility: A critical review of five decades' evidence. Journal of Applied Social Psychology, 34, 243-281.

Phua, J. (2016). The effects of similarity, parasocial identification, and source credibility in obesity public service announcement (PSAs) on diet and exercise self-efficacy. Journal of Health Psychology, 21, 699-708.

Quick, B. L., \& Bates, B. R. (2010). The use of gain- or loss- frame messages and efficacy appeals to dissuade excessive alcohol consumption among college students: A test of psychological reactance theory. Journal of Health Communication, 15, 603-628.

Quick, B. L., \& Considine, J. R. (2008). Examining the use of forceful language when designing exercise persuasive messages for adults: A test of conceptualizing reactance arousal as a two-step process. Health Communication, 23, 483-491.

Quick, B. L., Shen, L., \& Dillard, J. P. (2013). Reactance theory and persuasion. In J. P. Dillard \& L. Shen (Eds.), The Sage handbook of persuasion: Advances in theory and research ( $2^{\text {nd }}$ ed., pp. 167-183). Los Angeles, CA: Sage. 
Quick, B. L., \& Stephenson, M. T. (2007a). The reactance restoration scale (RRS): A measure of direct and indirect restoration. Communication Research Report, 24, 131-138.

Quick, B. L., \& Stephenson, M. T. (2007b) Further evidence that psychological reactance can be modeled as a combination of anger and negative cognition. Communication Research, 34, 255-276.

Quick, B. L., \& Stephenson, M. T. (2008). Examining the role of trait reactance and sensation seeking on perceived threat, state reactance, and reactance restoration. Human Communication Research, 34, 448-476.

Rains, S. A. (2013). The nature of psychological reactance revisited: A meta-analytic review. Human Communication Research, 39, 47-73.

Rains, S. A., \& Turner, M. M. (2007). Psychological reactance and persuasive health communication: A test and extension of the intertwined model. Human Communication Research, 33, 241-269.

Richards, A. S., \& Banas, J. A. (2015). Inoculating against reactance to persuasive health messages. Health Communication, 30, 451-460.

Ritter, J. (2000). Fresh rise in HIV rate rings alarms: Prevention burnout and a return of risky sexual behavior among gay men. USA Today: July 31, 2000. Available from: CDC National Prevention Information Network: News Record \# 30430.

Salmon, C. T. \& Atkin, C. (2003). Using media campaigns for health promotion. In T. L Thompson, A. M. Dorcey, K. I. Miller, R. Parrot (Eds.), The handbook of health communication (pp. 449-472). Mahwah, NJ: Lawrence Erlbaum. 
Sensening, J., \& Brehm, J. W. (1968). Attitude change from an implied threat to attitudinal freedom. Journal of Personality and Social Psychology, 8, 324-330.

Shen, L. (2010). Mitigating psychological reactance: The role of message-induced empathy in persuasion. Human Communication Research, 36, 397-422.

Shen, L. (2014). Antecedents to psychological reactance: The impact of threat, message frame, and choice. Health Communication, 30, 975-985.

Shirong Lu, A. (2013). An experimental test of the persuasive effect of source similarity in narrative and nonnarrative health blogs. Journal of Medical Internet Research, 15(7), e142, doi: 10.2196/jmir.2386

Silvia, P. J. (2005). Deflecting reactance: The role of similarity in increasing compliance and educing resistance. Basic and Applied Social Psychology, 27, 277-284.

Smith, M. J. (1977). The effects of threats to attitudinal freedom as a function of message quality and initial receiver attitude. Communication Monographs, 44, 196-206.

Snoeck-Henkemans, F. (2010). 'Anyway' and 'even' as indicators of complex argumentation. Cogency. Journal of Reasoning and Argumentation, 2, 81-94.

Steindl, C., Jonas, E., Sittenthaler, S., Traut-Mattaush, E., \& Greenberg, J. (2015). Understanding psychological reactance. New developments and findings. Zeitschrift fur Psychologie, 223, 205-214.

Stockman, J., Schwarcz, S., Butler, L., de Jong, B., Chen, S., Delgado, V., \& McFarland, W. (2004). HIV prevention fatigue among high-risk populations in San Francisco. Journal of Acquired Immune Deficiency Syndromes, 35, 432-434. 
Van Gerrevink, R., \& de Hoop, H. (2007). On the optimal use of almost and barely in argumentation. In M. Aloni, P. Dekker, \& F. Roelofsen (Eds.), Proceedings of the $16^{\text {th }}$ Amsterdam Colloquium (pp. 229-235). ILLC, University of Amsterdam.

Van't Riet, J., \& Ruiter, R. A. C. (2013). Defensive reactions to health-promoting information: An overview and implications for future research. Health Psychology Review, 7, 104136.

Verhagen, A. (2008). Intersubjectivity and the architecture of the language system. In J. Zlatev, T. P. Racine, C. Sinha, \& E. Itkonen (Eds.), The shared mind. Perspectives on intersubjectivity (pp. 307-331). Philadelphia, PA: John Benjamins.

Wagner, H. S., Howland, M., \& Mann, T. (2015). Effects of subtle and explicit health messages on food choice. Health Psychology, 34, 79-82.

Webster, D. M., \& Kruglanski, A. W. (1997). Cognitive and social consequences of the Need for Cognitive Closure. European Review of Social Psychology, 8, 133-173.

Wicklund, R. A. (1974). Freedom and reactance. Potomac, MD: Lawrence Erlbaum.

Winterstein, G., \& Schaden, G. (2011). Relevance and utility in an argumentative framework: An application to the accommodation of discourse topics. In A. Lecomte, \& S. Tronçon (Eds.), Ludics, dialogue and interactions (pp. 134-146). Berlin, Germany: Springer-Verlag.

Woller, K. M. P., Buboltz, W. C., \& Loveland, J. M. (2007). Psychological reactance: Examination across age, ethnicity, and gender. The American Journal of Psychology, $120,15-24$. 
Wong, N. C. H., Harrison, K. J., \& Harvell, L. A. (2015). Reactance and public health messages: The unintended dangers of anti-tobacco PSAs. Studies in Media and Communication, 3, 72-83.

\section{Author Biographies}

Vincent Coppola is assistant professor of Social Psychology at the Tarbes University Institute of Technology in the Department of Corporate and Administrative Management (Tarbes, France). His main research interests concern persuasive communication and attitude change with applications in HIV/AIDS prevention, the role of some linguistic devices in the persuasion process and the HIV/AIDS media representation construction.

Fabien Girandola is full professor of Social Psychology at Aix-Marseille Université (Aix-en-

Provence, France). His research focuses on social influences: persuasive communication and resistance to persuasion, dissonance, binding communication, social representation more specifically in the domains of public health and environment. 